\title{
The welfare effect of access to credit
}

\author{
Mariana Rojas Breu*
}

June 2010

\begin{abstract}
I present a model in which credit and outside money can be used as means of payment in order to analyze how access to credit affects welfare when credit markets feature limited participation. Allowing more agents to use credit has an ambiguous effect on welfare because it may make consumption-risk sharing more inefficient. I calibrate the model using U.S. data on credit-card transactions and show that the increase in access to credit from 1990 to the near present has had a slightly negative impact on welfare.

Keywords : money, credit, risk sharing, limited participation JEL Classification: E51, E41
\end{abstract}

\footnotetext{
*I would like to specially thank Aleksander Berentsen. I also thank Vincent Bignon, Régis Breton, Jean Cartelier, Miquel Faig, Cyril Monnet, Casper de Vries, Christopher Waller, Makoto Watanabe, Warren Weber, Pierre-Olivier Weill and Randall Wright for very helpful discussions and suggestions, as well as participants at the Symposium on Money and Banking (Rennes), Money, Macro and Finance Conference (Birmingham), Chicago Fed Workshop on Money, Banking and Payments, AFSE Conference (Paris), T2M Conference (Cergy), and seminars at University of Basel and University of Paris X. This paper was finished while I was visiting the Federal Reserve Bank of St. Louis. I acknowledge financial support from the Swiss National Science Foundation. Any errors are my own.

Mariana Rojas Breu: Swiss National Science Foundation \& Visiting Researcher at Erasmus School of Economics. Phone: +31 (0)10 408 1425, Fax: +31 (0)10 408 9161, E-mail: mariana.rojas-breu@unibas.ch
} 


\section{Introduction}

In modern economies, two types of money are widely used: outside money (i.e. notes and coins issued by central banks) and inside money issued by commercial banks (e.g., checks or credit cards). Transactions do not only differ in the monetary instrument used: Whereas some of them involve a credit operation, like those carried out with credit cards, others require the acquisition of money balances prior to the transaction. Over the last few decades, major changes have occurred in consumer methods of payments, owing to a large extent to technological improvements which have substantially altered the convenience of using plastic money as opposed to paper money. In particular, the relative importance of transactions conducted with credit cards has increased compared to transactions in which no credit is granted. While at the beginning of the 1970s all general-purpose payment cards (including credit cards) only accounted for less than $2 \%$ of the volume of all consumer expenditures, in the late 2000s about one fifth of the expenditures were settled with credit cards. Factors like the reduction in the time to process credit-card transactions, the decline in the cost of telecommunications, or the enhancement of bank techniques for screening and monitoring an increasing number of customers are crucial in explaining the observed rise in the share of credit transactions. $^{1}$

However, outside money is still extensively used. For instance, in 2008 in the United States, payments in cash accounted for $20.9 \%$ of the volume of consumer transactions and $33.7 \%$ of the number of consumer transactions. ${ }^{2}$ This observation suggests that credit is not available in numerous circumstances and hence that participation in the credit markets is limited. ${ }^{3}$ The estimation by the Survey of Consumer Finances that $27.3 \%$ of U.S. households did not have a general-purpose bank-type credit card in 2001 is further evidence of limited participation in credit markets.

\footnotetext{
${ }^{1}$ For a history of credit cards, see Evans and Schmalensee (2005).

${ }^{2}$ The Nilson Report, December 2009. The share of all paper-based monetary instruments in 2008 was $42.8 \%$ in value and $48.1 \%$ in the number of transactions.

${ }^{3}$ See Telyukova (2009) for a discussion on how to classify expenditures between those for which consumers had the option to use credit cards and those that could only be settled with cash in recent years.
} 
In this paper, I analyze the welfare implications of the increased use of credit as a means of payment in the presence of limited participation in the credit market. For this, I build a microfounded monetary model à la Lagos and Wright (2005) in which agents can use both credit issued by financial intermediaries and outside money as media of exchange. ${ }^{4}$ The model presented captures the main feature that distinguishes credit from money: While credit allows delaying settlement if an opportunity of consumption arises, money balances must be held in advance in order to settle a transaction and therefore are exposed to inflation. To study an economy with limited participation in the credit market, I assume that the use of bank credit in trade depends upon the availability of a technology: e.g., credit cards can only be used if a card reader is available. This technology determines the number of transactions that can be settled with credit every period. Since agents face uncertainty regarding their ability to use credit, a precautionary demand for money emerges endogenously.

In this model, inflation deteriorates welfare by two channels. First, as is usual in monetary models, inflation reduces lifetime consumption by increasing the marginal cost of holding money. In addition, inflation negatively affects welfare because it makes consumption-risk sharing less efficient. Since it reduces consumption by agents in periods in which they cannot borrow and increases consumption by agents when they are able to use credit, agents are less able to smooth consumption across periods.

The model presented is suitable for studying the consequences of a technological improvement in the credit sector which allows agents to resort to credit more often and thereby gives rise to a higher share of credit transactions. Interestingly, broadening the use of credit has an ambiguous effect on welfare, because it can make consumption-risk sharing more inefficient. As stated by Green (2001), several studies, like Schreft (1992) and Aiyagari, Braun and Eckstein (1998), predict that greater innovation in the credit sector would reduce the welfare cost of inflation. Indeed, an increase in access to credit is expected to generate a welfare gain stemming from a lower exposure to inflation: If agents can rely more on credit, they

\footnotetext{
${ }^{4}$ Throughout this paper, the terms "credit" and "inside money" are used indistinguishably since credit is the only type of inside money that I allow for in the model presented.
} 
can reduce their money holdings and hence suffer a lower impact from inflation. However, I calibrate the model to U.S. data and show that the improvement in the credit sector that yielded a wider use of credit cards from 1990 to the near present entailed a negative welfare gain. The reason is that consumption-risk sharing became more inefficient.

In addition, the quantitative analysis allows me to calculate the welfare cost of inflation when credit is available, thus advancing the literature that aims at introducing the banking sector into the computations of the welfare cost of inflation. The refinements to these calculations have consisted mainly in taking the interest-bearing assets (in particular, bank deposits) in agents' monetary holdings into consideration, which are shown to affect the estimates of the cost of inflation. ${ }^{5}$ Influencial work by Dotsey and Ireland (1996) and Lacker and Schreft (1996), which incorporated credit within the analysis of the welfare cost of inflation, emphasized the diversion of resources to the credit sector. Instead, I calculate the welfare cost of inflation taking into account limited participation in the credit market. I find that reducing annual inflation from $10 \%$ to $0 \%$ is worth slightly more than $1 \%$ of steady-state output.

Several papers have investigated the effects of technological changes affecting money demand. Faig and Jerez (2007) develop a model that is able to account for the decline in money demand in the U.S. by integrating technological factors that have made portfolio adjustments easier. English (1999) studies the relationship between inflation and financial sector size. His model predicts an ambiguous effect of an increase in the productivity of the financial sector on welfare, although this depends on the assumption that inflation does not distort labor and saving decisions. My work is also related to Reed and Waller (2006) who assume heterogeneity across agents arising from endowment shocks to study how money can help to overcome inefficient risk sharing. Aiyagari and Williamson (2000) also study the distribution of consumption and welfare in a framework with dynamic contracts offered by financial intermediaries, limited participation and private information. However, in these papers, the consequences of increased access to credit are not analyzed. ${ }^{6}$

\footnotetext{
${ }^{5}$ See Simonsen and Cisne (2001), Alvarez and Lippi (2009) and Attanasio, Guiso and Jappelli (2002).

${ }^{6}$ Other articles considered limited participation in the credit market for different purposes. For instance,
} 
The rest of the paper proceeds as follows. In Section II the model is described. In Section III I define the symmetric equilibrium and point out its main features. Section IV is devoted to the quantitative analysis. Finally, Section V concludes.

\section{The model}

The original framework I build on is the divisible-money model by Lagos and Wright. The main advantage of this framework is that it facilitates the introduction of heterogeneity in production and consumption preferences as well as the divisibility of money, keeping the distribution of money holdings degenerate and, thus, analytically tractable. Similar to Berentsen, Camera and Waller (2007), I introduce banks. The difference is that, while in their model banks redistribute money from depositors to borrowers, I allow banks to issue credit with no reserve requirements. I do not allow agents to deposit money and earn interest on it as in Berentsen et al. because my focus is on the consequences of credit.

Time is discrete and infinite. There is a continuum of infinitely lived agents of unit mass and one perfectly divisible and non-storable good. Agents discount across periods with factor $\beta \in(0,1)$. In each period, two competitive markets open sequentially. Before the first market opens, agents get a preference shock by which they either want to consume but cannot produce (with probability $(1-s)$ ) or can produce but do not want to consume (with probability $s$ ). I call "buyers" the agents who get the first type of shock and "sellers" those who get the second type. In the first market, buyers get utility $u(q)$ when they consume a quantity $q$ of the unique good, with $u^{\prime}(q)>0, u^{\prime \prime}(q)<0, u^{\prime}(0)=+\infty$ and $u^{\prime}(\infty)=0$.

For sellers, producing a quantity $q$ represents a disutility equal to $c(q)$ with $c^{\prime}(q)>0$ and Monnet and Roberds (2008) develop a model to rationalize the "no-surcharge rule" by which no premium should be applied to purchases with credit cards. Many recent theoretical papers have analyzed the coexistence of outside money and credit or inside money in a microfounded framework of monetary exchange, like Shi (1996), Cavalcanti and Wallace (1999), He, Huang and Wright (2008), Williamson (1999, 2004), Telyukova and Wright (2008), and Li (2006, 2009). But they abstract from the risk-sharing dimension of the extension of credit explored in this paper. 
$c^{\prime \prime}(q) \geqslant 0$

In the second market all agents can consume and produce. Consuming $x$ gives utility $U(x)$ with $U^{\prime}(x)>0$ and $U^{\prime \prime}(x) \leqslant 0$. Disutility cost from producing $x$ is equal to $h$, where one unit of labor yields one unit of the consumption good.

In addition, there is an intrinsically useless object I refer to as outside money. The supply of outside money is subject to central bank decisions which are considered as exogenous. I call $M_{t}$ the per capita money stock in period $t$. The money stock grows at a rate $\gamma$ with $\gamma>0$. Agents receive lump-sum transfers equal to $(\gamma-1) M_{t-1}$ during the second market in $t$, where the subscript -1 indicates the previous period (and +1 indicates the following period). Thus $M_{t}=\gamma M_{t-1}$.

In order to motivate a role for money, traders are assumed to be anonymous so that sellers require compensation simultaneously as they produce. This assumption rules out bilateral credit; however, it does not conflict with the existence of lending in this model because this only requires that agents are identified by banks.

Credit is issued as a bilateral contract between an agent and a bank by which the bank gives an amount $l$ of inside money to the agent before the first market opens and the agent must pay it back at the end of the period. ${ }^{7}$ Banks have enforcement power; thus default and, consequently, loan size are not an issue. ${ }^{8}$

Banks are competitive and operate at zero cost so that credit is costless for traders. This assumption is made for simplicity but justified in that the model focuses on the extension of credit within the period. Thus, it is well-suited for accounting for the convenience credit granted by credit-cards issuers during the grace period, for which no interest is charged. ${ }^{9}$

\footnotetext{
${ }^{7} \mathrm{I}$ do not explicitly include an exchange rate between inside and outside money (it is set to 1 ). This is with no loss, since I will only consider stationary equilibria in which the real amount of money balances and the real amount of loans are time-invariant.

${ }^{8}$ Berentsen et al. also consider the case in which banks have no enforcement power, because they aim at studying the relationship between inflation and default. Given my purpose, I only consider the simpler setting of full enforcement.

${ }^{9}$ Since my ultimate aim is to quantitatively analyze the increased use of credit cards, I also assume away fixed costs in the use of credit based on the fact that most credit cards do not charge annual fees.
} 
Access to credit is determined by an exogenous technology. In each period, agents face a probability $\delta$ of being able to borrow. Hence, participation in the credit market is idiosyncratic and random, as in the cited work by Aiyagari and Williamson and Monnet and Roberds, among others. This modeling choice will be suitable for reflecting that technological improvements affecting credit cards have translated into a higher probability for buyers of being able to conduct a transaction with credit. ${ }^{10}$ Agents learn whether they will be able to borrow simultaneously to learning that they are buyers.

\section{Symmetric equilibrium}

I will consider symmetric and stationary equilibria in which strategies are the same across agents, real allocations are constant over time, $\gamma$ is time-invariant and end-of-period real money balances are constant, so I ignore index $t$. This implies $\phi M=\phi_{+1} M_{+1}$, where $\phi$ is the price of money in the second market in a given period, and

$$
\gamma=M_{+1} / M=\phi / \phi_{+1}
$$

I indicate by $W(m, l)$ the expected value of entering the second market with an amount $m$ of money and an amount $l$ of loans. $V(m)$ is the expected value of entering the first market with an amount $m$ of money. In this section, the model is solved backwards for a representative period.

\subsection{The Second Market}

In the second market, agents consume $x$, produce $h$, repay credit borrowed at the beginning of the current period $(l)$ and choose the amount of outside money that they will take into Furthermore, most convenience users receive rewards for using their credit cards as described by Evans and Schmalensee.

${ }^{10}$ For instance Humphrey (2004) finds that a larger use of credit cards is closely related to the diffusion of card terminals. 
the following period $\left(m_{+1}\right)$. The representative agent's program is

$$
\begin{aligned}
& W(m, l)=\max _{x, h, m_{+1}}\left[U(x)-h+\beta V_{+1}\left(m_{+1}\right)\right] \\
& \text { s.t. } x+\phi m_{+1}=h+\phi\left[m-l+(\gamma-1) M_{-1}\right]
\end{aligned}
$$

After inserting the budget constraint into (2), the first-order conditions are

$$
U^{\prime}(x)=1, \beta V_{+1}^{\prime}\left(m_{+1}\right)=\phi
$$

where $V_{+1}^{\prime}\left(m_{+1}\right)$ is the marginal value of outside money taken into the following period. The envelope conditions are

$$
W_{m}=\phi, \quad W_{l}=-\phi
$$

\subsection{The First Market}

The expected lifetime utility for an agent who holds an amount $m$ of money before entering the first market is

$$
\begin{aligned}
V(m) & =(1-s) \delta\left[u\left(q_{\ell}\right)+W\left(m+l-p q_{\ell}, l\right)\right] \\
& +(1-s)(1-\delta)\left[u\left(q_{n}\right)+W\left(m-p q_{n}, 0\right)\right] \\
& +s\left[-c\left(q_{s}\right)+W\left(m+p q_{s}, 0\right)\right]
\end{aligned}
$$

where $p$ is the price of the good in the first market. $q_{\ell}$ is the quantity of good that the buyer consumes when he is able to borrow, $q_{n}$ is the quantity that he consumes if he is not able to borrow, and $q_{s}$ is the quantity the seller sells in exchange for an amount of money equal to $p q_{s}$.

Denote $m_{-1}$ as the amount of money brought by the representative agent from the previous period. The problem for an agent who is a seller in the first market is

$$
\max _{q_{s}}\left[-c\left(q_{s}\right)+W\left(m_{-1}+p q_{s}, 0\right)\right]
$$

Using (4), the first-order condition is

$$
c^{\prime}\left(q_{s}\right)=\phi p
$$


Buyers face a different problem depending on whether they can borrow or not. The decision's variables for a buyer who is able to borrow are $q_{\ell}$ and $l$. His problem is to solve

$$
\begin{gathered}
\max _{q_{\ell}, l}\left[u\left(q_{\ell}\right)+W\left(m_{-1}+l-p q_{\ell}, l\right)\right] \\
\text { s.t. } p q_{\ell} \leq m_{-1}+l
\end{gathered}
$$

The buyer maximizes his utility subject to the cash constraint, which means that he cannot spend more money than the amount that he brings into the market. In the case of the buyer who can borrow, this amount is given by the sum of the money taken from the previous period and the amount of loans borrowed at the beginning of the current period. Since banks can fully enforce the repayment of loans, borrowers can borrow as much as they want and the cash-constraint is never binding for them. Using (4) and (6), first-order conditions on $q_{\ell}$ and $l$ yield

$$
u^{\prime}\left(q_{\ell}\right)=c^{\prime}\left(q_{s}\right)
$$

For a buyer who is not able to borrow inside money, the problem is to choose $q_{n}$

$$
\begin{gathered}
\max _{q_{n}}\left[u\left(q_{n}\right)+W\left(m_{-1}-p q_{n}, 0\right)\right] \\
\text { s.t. } p q_{n} \leq m_{-1}
\end{gathered}
$$

Using (4) and (6), the first-order condition reduces to

$$
u^{\prime}\left(q_{n}\right)=c^{\prime}\left(q_{s}\right)(1+\lambda / \phi)
$$

where $\lambda$ is the multiplier on the cash constraint for the agent unable to borrow.

From (5), the marginal value of outside money is

$$
V^{\prime}(m)=\phi+\phi(1-s)(1-\delta)\left[u^{\prime}\left(q_{n}\right) / c^{\prime}\left(q_{s}\right)-1\right]
$$

In a stationary equilibrium, I can use (3) lagged one period and (1) to obtain

$$
\gamma / \beta-1=(1-s)(1-\delta)\left[u^{\prime}\left(q_{n}\right) / c^{\prime}\left(q_{s}\right)-1\right]
$$

Finally, for market clearing, the following condition must hold in equilibrium:

$$
s q_{s}=(1-s)\left[\delta q_{\ell}+(1-\delta) q_{n}\right]
$$


Definition 1 A monetary equilibrium with both outside money and credit is $\left\{q_{n}, q_{\ell}, q_{s}\right\}$ satisfying (7), (9) and (10).

In order to characterize the equilibrium, I derive the planner's solution; i.e., consumption and production quantities that maximize welfare. Since I assume that all agents are treated symmetrically, maximizing welfare implies maximizing the expected steady-state lifetime utility of the representative agent, which is

$$
(1-\beta) \mathcal{W}=(1-s)\left[\delta u\left(q_{\ell}\right)+(1-\delta) u\left(q_{n}\right)\right]-s c\left(q_{s}\right)+U(x)-x
$$

while the feasibility constraint is

$$
s q_{s}=(1-s)\left[\delta q_{\ell}+(1-\delta) q_{n}\right]
$$

The planner maximizes (11) subject to (12) to get the first-best allocation. This satisfies

$$
U^{\prime}\left(x^{*}\right)=1, \quad u^{\prime}\left(q_{\ell}^{*}\right)=u^{\prime}\left(q_{n}^{*}\right)=c^{\prime}\left(q_{s}^{*}\right)
$$

Thus, welfare maximization implies $q_{n}^{*}=q_{\ell}^{*}=q^{*}$ where $q^{*}$ is defined by

$$
u^{\prime}\left(q^{*}\right)=c^{\prime}\left(q^{*}(1-s) / s\right)
$$

Proposition 1 a) If $\gamma>\beta$ and $\delta \in(0,1)$, a unique monetary equilibrium with both outside money and credit exists. If $c^{\prime}\left(q_{s}\right)>1, q_{n}$ and $q_{\ell}$ satisfy $q_{n}<q^{*}<q_{\ell}$. b) If $\delta=1$ and $\gamma>\beta$, outside money is driven out by credit. $q_{\ell}$ satisfies $q_{\ell}=q^{*}$. c) If $\gamma=\beta$ and $\delta \in(0,1)$, credit is driven out by outside money. $q_{n}$ and $q_{\ell}$ satisfy $q_{n}=q_{\ell}=q^{*}$.

Proof. See appendix.

According to Proposition 1, a unique equilibrium exists in which both outside money and credit are used, when the economy is away from the Friedman rule and the event of not being able to borrow in the following period occurs with some probability. The consumption quantity that the buyer who is not able to borrow attains is lower than the consumption quantity acquired by the buyer able to borrow. This is because the former 
is cash-constrained. With outside money only, the efficient consumption quantity cannot be attained since a positive inflation requires a higher marginal value of outside money for agents to accept it, which is equivalent to a higher marginal utility from consumption, and thus a lower consumption quantity.

Buyers who borrow get a consumption quantity that is higher than the efficient quantity defined in (13). This is because these buyers benefit from the constraint on the buyers who cannot borrow which keeps the sellers' marginal cost below the marginal cost at the efficient quantity. Thus, in this equilibrium there is inefficient consumption-risk sharing across buyers.

If $\delta=1$ and $\gamma>\beta$, nobody is willing to hold outside money, as outside money need not play the insurance role anymore. Therefore, an equilibrium with outside money cannot be sustained. On the contrary, when $\gamma=\beta$ and $\delta \in(0,1)$, credit turns out to be useless because outside money becomes a costless way of acquiring consumption. Agents take the necessary amount of outside money across periods in order to get efficient trade and can refrain from borrowing. ${ }^{11}$ In both equilibria with either credit or outside money, consumption-risk sharing is efficient. For the rest of the analysis, I will focus on the case $\gamma>\beta$ and $\delta<1$.

Proposition $2 q_{n}$ and $q_{s}$ are decreasing in $\gamma$. If $c^{\prime}\left(q_{s}\right)>1$, $q_{\ell}$ is increasing in $\gamma$. An increase in $\gamma$ is welfare-worsening.

Proof. Immediate from (7), (9), (10) and (11).

Proposition 2 states that an increase in inflation has an asymmetric effect on buyers. Consumption quantity decreases for buyers who cannot borrow and increases for buyers who can borrow, since the latter benefit from a higher constraint on buyers who use only outside money. Overall production decreases and welfare worsens because higher inflation makes consumption-risk sharing more inefficient; i.e., consumption decreases for buyers whose marginal utility is higher and increases for those whose marginal utility is lower. ${ }^{12}$

\footnotetext{
${ }^{11}$ Given that borrowing is costless, multiple equilibria with different amounts of $l$ exist when $\gamma=\beta$.

${ }^{12}$ This result is similar to those in studies already cited by Reed and Waller and Aiyagari and Williamson.
} 
Proposition $3 q_{n}$ is decreasing in $\delta$ while the effect of $\delta$ on $q_{\ell}$ and $q_{s}$ is ambiguous. An increase in $\delta$ has a negative effect on welfare along the intensive margin and a positive effect along the extensive margin. The overall effect on welfare is ambiguous.

Proof. See appendix.

When $\delta$ increases, $q_{n}$ certainly decreases, while this is not always the case for $q_{\ell}$. Buyers face a different situation when $\delta$ increases depending on whether they have access to credit or not. $q_{s}$ can decrease or increase when $\delta$ increases depending on parameters' values, so borrowers could consume either more or less: They adjust their marginal utility to the marginal cost of sellers. However, an increase in $\delta$ has a direct effect that affects only buyers who do not borrow. As can be seen from (9), increasing $\delta$ reduces the marginal value of money. Therefore, agents desire a lower level of money holdings to be taken across periods, which reduces the price of money. As a result, buyers who cannot borrow are more cashconstrained and consume less.

The effect of an increase in $\delta$ on welfare is ambiguous because it makes some high-marginal utility buyers consume more and some consume less. We can interpret it as the combination of an extensive-margin effect and an intensive-margin effect. The extensive-margin effect consists in an increase in consumption and production owing to a higher measure of agents who can borrow; i.e., $u\left(q_{\ell}\right)-u\left(q_{n}\right)-c^{\prime}\left(q_{s}\right)\left(q_{\ell}-q_{n}\right)$, which is unambiguously positive. The intensive-margin effect reflects the changes in quantities traded as a consequence of an increase in $\delta$. This effect is always negative for non-borrowers and sufficient for a negative intensive-margin effect when computing welfare for the whole population. The reason is that borrowers get efficient trade in equilibrium, so that an increase (decrease) in their utility is exactly compensated for by an increase (decrease) in sellers' disutility. The overall intensive margin-effect is then $(1-\delta)\left(\partial q_{n} / \partial \delta\right)\left[u^{\prime}\left(q_{n}\right)-c^{\prime}\left(q_{s}\right)\right]<0 .{ }^{13}$

Note that the ambiguity of the effect of an increase in $\delta$ does not hinge on the existence of a strictly convex cost function. A linear cost function would make it possible to determine

\footnotetext{
${ }^{13}$ I have examined a version of this model in which one group of agents can borrow permanently while another group is excluded from the credit market. The effect of $\delta$ is also ambiguous in that case.
} 
$q_{\ell}$ independently of $\gamma$ and $\delta$, but there would still be a positive effect of an increase in $\delta$ given by the larger measure of agents consuming $q_{\ell}$ and a negative effect given by a lower $q_{n}$. Analogously, assuming bilateral bargaining in the first market would make $q_{\ell}$ be independent of $\gamma$ and $\delta$, but the existence of a positive extensive-margin effect and a negative intensivemargin effect would be preserved.

\section{Quantitative analysis}

Given that the formal analysis does not admit a conclusion on how an increase in $\delta$ affects welfare, I proceed to a calibration of the theoretical model. In addition, the calibration allows me to measure the welfare cost of inflation in the presence of limited participation in the credit market as well as the cost of inefficient risk sharing arising from limited participation.

The basic feature of the model presented is the existence of two types of transactions: those which involve a credit operation and those which are immediately settled and hence require an investment in the form of money balances. Among the payment instruments actually used, I identify the former with the use of credit cards and the latter with the use of monetary instruments such as cash, debit cards, and checks. Revolving credit does not arise in this model owing to the quasi-linear preferences in the settlement stage, so that credit is extended within the period. I interpret this credit operation as the grace period granted by credit card issuers, during which no interest is charged on the outstanding balance. This credit operation is usually referred to as convenience credit. My analysis concerns the effect of the availability of convenience credit for a subset of transactions, those carried out with credit cards, whereas the rest of transactions are immediately settled. ${ }^{14}$

\footnotetext{
${ }^{14}$ I consider convenience credit instead of total consumer credit because the former can be identified in its use as a means of payment and hence linked to the purchase of goods and services, whereas total consumer credit includes loans that may have other purposes not related to the mechanism highlighted in this paper (e.g., the repayment of other debts). Convenience credit can also be imputed to a particular period.
} 


\subsection{Calibration}

I use U.S. data for the period 1959-2003, with the exception of data on credit-card transactions which have only become available in recent years. I use the following functional forms generally used in the literature: $u(q)=\left(q^{\alpha}\right) / \alpha, U(x)=B \ln (x)$ and $c\left(q_{s}\right)=q_{s}$ (below I consider a strictly convex cost function). The parameters to be identified are: (i) preference parameters: $\beta, \alpha, B$; (ii) technology parameters: $\delta, s$; and (iii) a policy parameter: $\gamma$.

For my baseline calibration, I follow Lucas (2000) and Lagos and Wright and calibrate the model so as to fit the observed relationship between yearly money demand and the nominal interest rate during the sample period. I consider data on money demand and the commercial paper rate, denoted by $i=\gamma / \beta-1 .^{15}$ I normalize $s=0.5$ so as to make the calibration comparable with the one in Lagos and Wright, who equate the probability of a singlecoincidence meeting in which the agent is a seller to 0.5 for most of their specifications (in the robustness section, I present an alternative calibration which determines $s$ ). I determine the value of $\delta$ by using the ratio $\kappa$ of the number of transactions carried out with credit cards to the number of all transactions. In the model, borrowers carry out one transaction with money and one transaction with credit, whereas non-borrowers carry out only one transaction with money. Sellers purchase goods during the second market; they carry out one transaction for which no credit is granted. Thus, $\kappa$ is:

$$
\kappa \equiv \delta(1-s) /[1+\delta(1-s)]
$$

The average value of $\kappa$ for the period $1990-2003$ is $0.167 .{ }^{16}$ Therefore, $\delta=0.402$. In order to identify the remaining parameters $(\alpha, B)$, I find the best fit to yearly money

\footnotetext{
${ }^{15}$ The interest rate is the short-term commercial paper rate, taken from the Economic Report of the President (2009, Table B-73). For the computation of money demand I use the following data: The money supply is M1 in billions of dollars, December of each year, not seasonally adjusted, taken from the Federal Reserve Bank of St. Louis FRED Database; the real gross domestic product is in billions of chained (2000) dollars, taken from the Economic Report of the President (2009, Table B-2); the implicit price deflator for GDP equals 1.0 in 2000 and is taken from the National Income and Product Accounts of the United States.

${ }^{16}$ The Nilson Report and Statistical Abstract of the United States, several years. The period to compute $\kappa$ is based on data availability. Transactions considered are conducted with checks, cash, money orders, official
} 
demand. In the model the household's money balance is $m=p q_{n}$; nominal output is $p(1-s)\left[\delta q_{\ell}+(1-\delta) q_{n}\right]$ in the first market and $x^{*} / \phi=B / \phi$ in the second market. Then, money demand $L$ satisfies

$$
L \equiv q_{n} /\left\{(1-s)\left[\delta q_{\ell}+(1-\delta) q_{n}\right]+B\right\}
$$

When fitting money demand I set $\delta$ equal to 0 to facilitate a comparison with previous work (however, fitting money demand as a function of $i$ by taking into account changes in $\delta$ over time generates similar parameter values because estimated values of $\delta$ are small for most of the sample period). I get $\alpha=0.798$ and $B=2.524$.

\subsection{Welfare Analysis}

Table 1 illustrates the cost of inflation estimated with the calibrated model. I calculate it by computing how much consumption an agent would give up at $0 \%$ inflation rate to have the expected utility that corresponds to an annual rate of inflation of $10 \%$. With a slight abuse of notation, I write the agent's expected utility as a function of $(\gamma, \delta, \Delta)$, with $\Delta \geq 0$ :

$$
\begin{aligned}
& (1-\beta) V(\gamma, \delta, \Delta) \\
= & U\left(\Delta x^{*}\right)-x^{*}+(1-s)\left[\delta u\left(\Delta q_{\ell}(\gamma, \delta)\right)+(1-\delta) u\left(\Delta q_{n}(\gamma, \delta)\right)\right]-s c\left(q_{s}(\gamma, \delta)\right)
\end{aligned}
$$

I calculate the cost of $10 \%$ annual inflation as opposed to $0 \%$ inflation by finding the value $\Delta_{0}^{\gamma}$ that solves the following equation:

$$
V\left(1, \bar{\delta}, \Delta_{0}^{\gamma}\right)=V(1.1, \bar{\delta}, 1)
$$

where $\bar{\delta}$ is the calibrated value of $\delta$. I also calculate $\Delta_{F}^{\gamma}$, the factor that would render an agent indifferent between $10 \%$ of annual inflation and a rate of inflation consistent with the Friedman rule (i.e., $\gamma=\beta$ ). In the calibrated model, diminishing the yearly inflation checks, traveler's checks, food stamps, credit cards, debit cards, prepaid cards, EBT cards, preauthorized payments and remote payments. I consider all monetary instruments as money balances except for credit cards, even though other instruments, like checks, may involve a shorter credit operation. 
from $10 \%$ to $0 \%$ is worth $1.061 \%$ of steady-state consumption, while diminishing the yearly inflation from $10 \%$ to $-4 \%$ is worth $1.286 \%$ of steady-state consumption. This estimation is in line with those presented by Lucas (2000) and Lagos and Wright in the case where the buyer has all the bargaining power, the one that admits a comparison to a competitive pricing set-up. As stated in the description of the model, the reason why inflation deteriorates welfare is not only that it reduces lifetime consumption, but also that it makes risk sharing less efficient: The ratio $q_{n} / q_{\ell}$ is $53.7 \%$ at $0 \%$ inflation and only $14.3 \%$ at $10 \%$ annual inflation.

Table 1

Welfare cost of inflation \& welfare cost of an increase in $\delta$

\begin{tabular}{lccccc}
\hline & $\gamma=\beta$ & $\gamma=1$ & $\gamma=1.1$ & $\delta=0.327(1990)$ & $\delta=0.418$ (2003) \\
\hline$q_{n} / q_{\ell}$ & 1.000 & 0.537 & 0.143 & 0.329 & 0.282 \\
$q_{s}$ & 1.000 & 0.723 & 0.487 & 0.548 & 0.582 \\
$1-\Delta_{0}^{\gamma}(\%)$ & & & 1.061 & & \\
$1-\Delta_{F}^{\gamma}(\%)$ & & & 1.286 & & 0.024 \\
$1-\Delta_{1990}^{\delta}(\%)$ & & & & & \\
\hline
\end{tabular}

Table 1 also reports the cost of inefficient consumption-risk sharing owing to an increased access to credit. I calculate what percentage of steady-state consumption would render agents indifferent between the value of $\delta$ in 1990 (0.327) and its value in 2003 (0.418), when inflation is kept at its average value $\bar{\gamma}=1.043 .{ }^{17}$ For this, I determine the factor $\Delta_{1990}^{\delta}$ that solves:

$$
V\left(\bar{\gamma}, 0.327, \Delta_{1990}^{\delta}\right)=V(\bar{\gamma}, 0.418,1)
$$

I find that the increase in $\delta$ which occurred between 1990 and 2003 has entailed a welfare loss equivalent to $0.024 \%$ of steady-state consumption. This figure seems reasonable, since it is not necessarily sensible to argue that a larger access to credit deteriorates welfare

\footnotetext{
${ }^{17}$ The inflation rate is the average change of the Consumer Price Index series for 1959-2003 from the FRED Database. Considering the average inflation for 1990-2003 gives rise to a slightly higher welfare loss.
} 
considerably. The point that I want to emphasize is that improvements in the credit sector that caused the number of borrowers to increase did not give rise to an overall welfare gain: The negative effect on the consumption of agents who are unable to borrow has been sufficiently strong compared to the benefit of broadening the set of circumstances in which agents may resort to credit. ${ }^{18}$

To see that this result pertains to a particular combination of parameter values, Figure 1 depicts the welfare cost of increasing $\delta$ as a function of $\delta$. I compute the percentage of steady-state consumption that would render agents indifferent between each depicted value of $\delta$ and a value $10 \%$ lower $\left(1-\Delta_{0.9}^{\delta}\right)$ when inflation is kept at its calibrated value. Welfare losses stemming from changes in risk sharing occur at relatively low values of $\delta$, for which the intensive margin effect happens to be quantitatively more important than the extensive margin effect. In contrast, increasing the access to credit is beneficial in terms of welfare for sufficiently high values of $\delta$. The reason is that the welfare cost of inflation is increasing in $\delta$ up to a critical point of $\delta$ and decreases for higher values of $\delta$.

The effect of an increase in $\delta$ also depends on the level of inflation. From Figure 1 it is clear that the threshold above which an increase in $\delta$ is welfare-improving is lower when inflation is higher: It is $\delta=0.583$ when yearly inflation is $4.3 \%$ and $\delta=0.255$ when yearly inflation is $10 \%$. This result is in accord with previous work in which credit may be supported in equilibrium despite being detrimental for welfare and in which credit is more likely to be welfare-improving if inflation is sufficiently high, as in Chiu and Meh (2008) and Dong (2009). However, credit is costless here so that welfare losses stem entirely from the general equilibrium effect by which a broader access to credit lowers the value of money and prevents agents from benefitting from optimal smoothness in consumption across periods.

\footnotetext{
${ }^{18}$ The fall in $q_{n}$ as a consequence of a reduction in money demand when $\delta$ increases is consistent with empirical findings. For instance, Duca and Whitesell (1995) find that ownership of credit cards in the U.S. is negatively related to checking balances.
} 


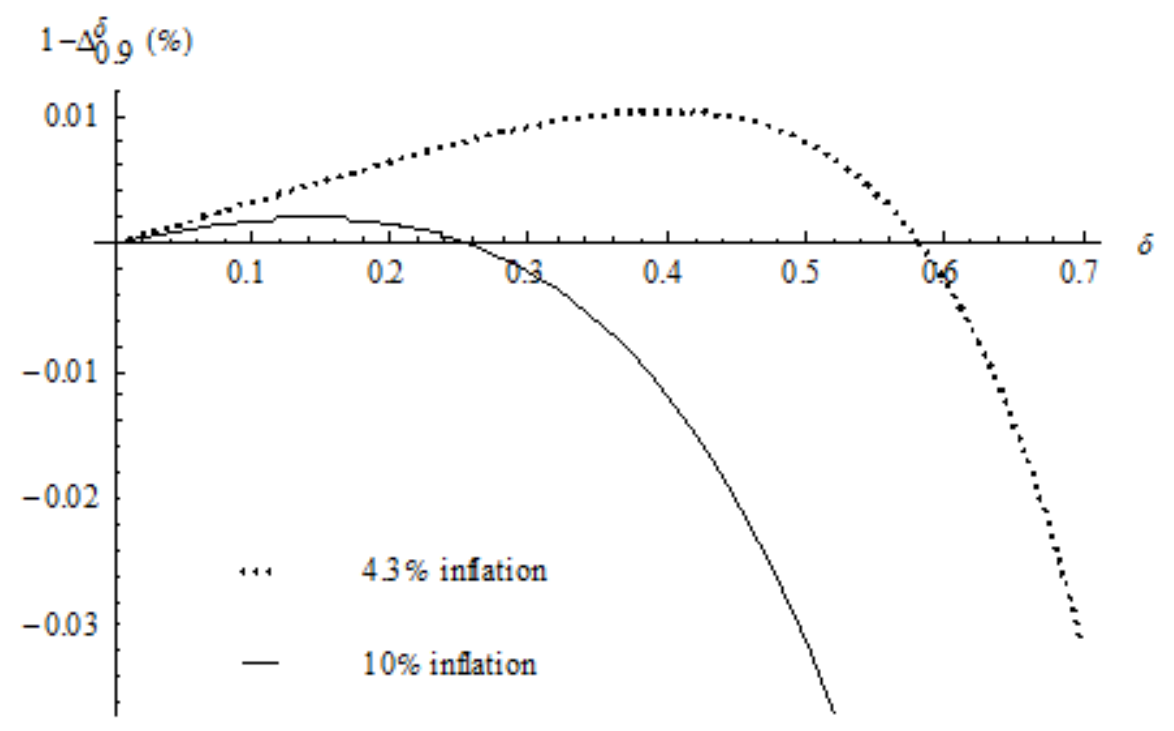

Figure 1. Welfare cost of an increase in $\delta$ as a function of $\delta$

\subsection{Robustness}

The results presented in the previous section are easily comparable with earlier work. Next, I repeat the procedure described above by setting a model period as a month, since it is the most suitable length to replicate the grace period granted by credit-card issuers. In addition, in order to assess how robust the results reported are, I recalibrate the model by using data on the credit-card share of transactions in volume. In this variant, the simulation results confirm the main pattern described above, suggesting that the identified relationship between access to credit and welfare is quite robust. Moreover, this calibration predicts a much stronger deterioration of welfare owing to the change in $\delta$ between 1990 and 2003 .

In the monthly version of the calibration presented above, only high values of $s$ are compatible with plausible parameters' values. The reason is that the model has to match a high level of money demand, which is increasing in $s$ (up to values of $s$ close to unity): If there are more sellers per consumer, the purchasing power of money increases so that the numerator in (14) increases whereas the denominator decreases. Thus, I set $s=0.9$. To test if results are sensitive to the cost function, I assume $c\left(q_{s}\right)=\left(q_{s}\right)^{\theta}$ and consider both $\theta=1$ 
and $\theta>1$. By fitting the observed relationship between monthly money demand and the interest rate, I get $\alpha=0.926, B=0.171$ and $\theta=1.002$, and $\alpha=0.924$ and $B=0.166$ when $\theta$ is set to 1 .

The procedure followed for the alternative calibration is to match the average value of the credit-card share of consumer payments in volume and other targets to characterize the steady-state allocations consistent with the data. As it is standard, $\beta$ is set so that the implied annual real interest rate is $4 \%$; i.e., $\beta=0.997$. The monthly average inflation for 1959-2003 gives $\gamma-1=0.351 \%$. $\theta$ is set to 1 . The remaining four parameters are identified jointly so as to match four targets: the ratio $\kappa$, the sample average of money demand (equal to 2.148 ), the ratio $\varkappa$ of the value of transactions carried out with credit cards to the value of all transactions and the interest elasticity of money demand $\xi$. In the model, $\varkappa$ is

$$
\begin{aligned}
\varkappa & \equiv(1-s) \delta l /\left\{(1-s)\left[\delta p q_{\ell}+(1-\delta) p q_{n}+\delta l+m\right]\right\} \\
& =\delta\left(q_{\ell}-q_{n}\right) /\left[2 \delta\left(q_{\ell}-q_{n}\right)+2 q_{n}\right]
\end{aligned}
$$

The numerator of $\varkappa$ shows the amount of credit spent by borrowers in each period. In the denominator, the values of all transactions in both markets are added together. By equating $\varkappa$ to the sample average of $20.9 \%$ of the ratio of credit-card transactions to total transactions in volume for the period 1990-2003, I get the third restriction to pin down $(\delta, s, \alpha, B)$.

In the model, the interest elasticity of money demand is:

$$
\xi \equiv\left[(1-s) \delta q_{\ell}+B\right] L(\gamma / \beta-1) /\left[(1-s)(1-\delta)\left(q_{n}\right)^{2} u^{\prime \prime}\left(q_{n}\right)\right]<0
$$

I obtain the fourth equation to pin down $(\delta, s, \alpha, B)$ by equating $\xi$ to -0.5 as generally reported in the literature (e.g., Hoffman \& Rasche, 1991). I get $s=0.774, \delta=0.886$, $\alpha=0.606$ and $B=0.042$. Table 2 summarizes the parameters' values from the two monthly calibrations considered: the baseline calibration, with linear and convex cost functions, and the calibration which matches the ratio $\varkappa$. 
Table 2

Parameters' values - Monthly Calibration

\begin{tabular}{lrrr}
\hline & Ratio $\varkappa$ & \multicolumn{2}{c}{ Fit money demand } \\
& & Linear cost & Convex cost \\
\hline$\delta$ & 0.886 & 0.402 & 0.402 \\
$s$ & 0.774 & 0.9 & 0.9 \\
$\theta$ & 1 & 1 & 1.002 \\
$B$ & 0.042 & 0.166 & 0.171 \\
$\alpha$ & 0.606 & 0.924 & 0.926 \\
\hline
\end{tabular}

Finally, Table 3 displays the welfare cost of the change in $\delta$ between 1990 and 2003 and the welfare cost of a yearly inflation of $10 \%$ for both of the calibrations performed. The calibrated parameters obtained by fitting monthly money demand generate estimates of the welfare cost of inflation and the welfare cost of the increase in $\delta$ that are similar to those computed with an annual model. In contrast, the calibrated model that is consistent with the ratio $\varkappa$ gives rise to a considerably higher welfare cost of an increase in $\delta$, equivalent to $0.319 \%$ of steady-state consumption. However, this cost appears to be lower for higher values of $\delta$ as in the baseline calibration.

Table 3

Welfare cost of inflation \& welfare cost of an increase in $\delta$

\begin{tabular}{lccc}
\hline & Ratio $\varkappa$ & \multicolumn{2}{c}{ Fit money demand } \\
& & Linear cost & Convex cost \\
\hline $1-\Delta_{0}^{\gamma}(\%)$ & 0.860 & 1.019 & 1.015 \\
$1-\Delta_{1990}^{\delta}(\%)$ & 0.319 & 0.021 & 0.021 \\
\hline
\end{tabular}


As verified by the values given in Table 3, the results do not depend upon the costfunction assumption. Since the preference parameters estimated when $\theta$ is set to 1 and when $\theta$ is fitted are similar, the implied welfare functions are also similar. Instead, the coefficient of risk aversion $(1-\alpha)$ is important to explain the shape of the welfare function. Simulations performed show that the welfare cost of increasing $\delta$ is decreasing in $(1-\alpha)$ up to a certain threshold and then increasing in it. When agents are too risk-averse, they protect themselves by holding higher money holdings; as a result, $q_{n}$ is higher and the reduction in $q_{n}$ owing to an increase in $\delta$ is lower (the intensive-margin effect is small). At the other extreme, when agents are almost risk-neutral, the reduction in $q_{n}$ does not negatively affect them provided that they consume $q_{\ell}$ more frequently which is the case when $\delta$ increases. Moreover, the welfare cost of an increase in $\delta$ is greatly determined by $B$ : When $B$ is low, the value of the foregone consumption that makes agents indifferent between two different values of $\delta$ is also low, so its quantity as a percentage of steady-state consumption has to be high. The combination of a medium value of $(1-\alpha)$ and a low value of $B$ explains that the alternative calibration generates a high cost of increasing $\delta$. In this sense, the baseline calibration gives conservative estimates of the welfare cost of the increase in $\delta$. Thus, the main results described seem to be robust with regard to the calibration procedure: In both of the calibrations presented the welfare cost of inflation appears to be a non-monotone function of $\delta$, increasing up to a certain value of $\delta$ and decreasing for higher values of $\delta$.

\section{Conclusion}

This paper presented a model in which outside money and credit are used as media of exchange in order to analyze how the existence of a credit market characterized by limited participation impacts on welfare when the economy is away from the Friedman rule. Inflation is shown to be unambiguously welfare-worsening as it makes consumption risk-sharing more inefficient, both across individuals and over time for a given agent. Technological improvements which allow the proportion of transactions that can be settled with credit each 
period to increase have an ambiguous impact on welfare as, on the one hand, they expand access to credit and, on the other hand, reduce the utility of non-borrowers.

The quantitative analysis shows that the increased access to convenience credit experienced in the United States since 1990 has not been beneficial in terms of welfare. Indeed, money demand has declined owing to the greater availability of credit as a means of payment, thereby tightening cash constraints when credit is not available. For plausible values of the coefficient of risk aversion, the utility gain achieved by using credit cards in a higher fraction

of purchases to relax the cash-constraint has not been sufficient to outweigh the loss resulting from being more cash-constrained when credit-card use is not possible. Consequently, agents have suffered from a higher exposure to inflation. This conclusion is obtained using two different quantitative procedures: The first one follows the approach of fitting the observed relationship between money demand and the interest rate and the second one uses data on the share of credit-cards transactions. However, the analysis presented suggests that, if agents were able to resort to credit more frequently, then the negative effect described might become less important and the improvements that increase the proportion of transactions settled using credit might actually be welfare improving. When access to credit is broadened sufficiently, the cost of inflation is more likely to be effectively reduced.

\section{Appendix}

Proof of Proposition 1: To see that there are only one quantity $q_{n}$ and one quantity $q_{\ell}$ that solve (7) and (9) when $\gamma>\beta$ and $\delta \in(0,1)$, insert (10) into (7) and (9) and compare the slope of the function $q_{\ell}\left(q_{n}\right)$ implicit in $(7)$ with the slope of the function $q_{\ell}\left(q_{n}\right)$ implicit in (9). I indicate the former by $\partial q_{\ell} / \partial q_{n}$ and the latter by $\hat{\partial} q_{\ell} / \hat{\partial} q_{n}$. From (7) and (9), the following can be deduced by using the implicit function theorem:

$$
\begin{aligned}
& \partial q_{\ell} / \partial q_{n}=c^{\prime \prime}\left(q_{s}\right)(1-s)(1-\delta)\left[u^{\prime \prime}\left(q_{\ell}\right) s-c^{\prime \prime}\left(q_{s}\right)(1-s) \delta\right]^{-1}<0 \\
& \hat{\partial} q_{\ell} / \hat{\partial} q_{n}=u^{\prime \prime}\left(q_{n}\right) c^{\prime}\left(q_{s}\right) s\left[u^{\prime}\left(q_{n}\right) c^{\prime \prime}\left(q_{s}\right)(1-s) \delta\right]^{-1}-(1-\delta) / \delta<0
\end{aligned}
$$


It follows that $\left|\partial q_{\ell} / \partial q_{n}\right|<\left|\hat{\partial} q_{\ell} / \hat{\partial} q_{n}\right|$ if and only if

$$
u^{\prime}\left(q_{n}\right) u^{\prime \prime}\left(q_{\ell}\right)(1-\delta) / c^{\prime}\left(q_{s}\right)+u^{\prime \prime}\left(q_{n}\right) \delta<s u^{\prime \prime}\left(q_{n}\right) u^{\prime \prime}\left(q_{\ell}\right) /\left[(1-s) c^{\prime \prime}\left(q_{s}\right)\right]
$$

The left-hand side in (15) is negative and the right-hand side is positive, so this inequality always holds. From (7), $q_{n} \rightarrow \infty$ when $q_{\ell} \rightarrow 0$ and $q_{\ell}=\breve{q}_{\ell}$ when $q_{n} \rightarrow 0$, where $\breve{q}_{\ell}$ satisfies $u^{\prime}\left(\breve{q}_{\ell}\right)=c^{\prime}\left(\delta \breve{q}_{\ell}(1-s) / s\right)$. From $(9), q_{\ell} \rightarrow \infty$ when $q_{n} \rightarrow 0$ and $q_{n}=\breve{q}_{n}$ when $q_{\ell} \rightarrow 0$, where $\breve{q}_{n}$ satisfies $u^{\prime}\left(\breve{q}_{n}\right) / c^{\prime}\left(\breve{q}_{n}(1-\delta)(1-s) / s\right)=(\gamma / \beta-1) /[(1-s)(1-\delta)]+1$. Since the slope of the second curve is steeper than the first one for all $q_{n}$ and the first curve intercepts only the axis $q_{\ell}$ at a finite number while the second curve intercepts only the axis $q_{n}$, both curves intersect in the space $\left(q_{n}, q_{\ell}\right)$ at only one point. If $c^{\prime}\left(q_{s}\right)=1, q_{n}$ and $q_{\ell}$ are independently and uniquely determined by (7) and (9).

That in equilibrium $q_{n}<q_{\ell}$ when $\gamma>\beta$ and $\delta \in(0,1)$ can be deduced from the concavity of $u(q)$ and (7) and (9). To see that $q_{\ell}>q^{*}$ when $c^{\prime}\left(q_{s}\right)>1$, compare (13) to (7). $\delta q_{\ell}+(1-\delta) q_{n}<q_{\ell}$ since $\delta<1$ and $q_{\ell}>q_{n}$. Then $u^{\prime}\left(q_{\ell}\right)<c^{\prime}\left(q_{\ell}(1-s) / s\right)$ which implies $q^{*}<q_{\ell}$. In addition, (13) implies $u^{\prime}(q)$ and $\check{c}^{\prime}(q)=c^{\prime}(q(1-s) / s)$ intersect at $q^{*}$ and $q_{\ell}>q^{*}$, so it must be that $q_{s}=\left[\delta q_{\ell}+(1-\delta) q_{n}\right](1-s) / s<q^{*}(1-s) / s$ for $(7)$ to hold. Hence, $q_{n}<q^{*}$.

If $\delta=1$ and $\gamma>\beta$, (9) cannot hold, which implies that $\beta V^{\prime}(m)<\phi_{-1}$ for all $m>0$. Thus $m^{*}=0$. If $\gamma=\beta$ and $\delta \in(0,1),(7)$ and (9) are identical. Therefore, $q_{n}=q_{\ell}=q^{*}$. To verify that $V(m)$ is concave so that the solution to (3) is well-defined, rewrite (8) as

$$
V^{\prime}(m)=(1-s)(1-\delta) u^{\prime}\left(q_{n}\right) / p+\phi[s+(1-s) \delta]
$$

Let $m^{*}=p q^{*}$. As long as $\delta<1$, if $m<m^{*}$ then $q_{n}<q^{*}$ which means $\partial q_{n} / \partial m>0$ so that $V^{\prime \prime}(m)<0$. If $m=m^{*}$ then $q_{n}=q^{*}$ and $\partial q_{n} / \partial m=0$, so $V^{\prime \prime}(m)=0$.

Proof of Proposition 3: From (7) and (9), it follows that $\partial q_{n} / \partial \delta<0$. Since the effect of $\delta$ on $q_{\ell}, q_{s}$ and welfare is ambiguous, it is sufficient to consider examples that exhibit an opposite relationship between $\delta$ and each of those variables. ${ }^{19}$ Differentiate (11) with respect to $\delta$. The

\footnotetext{
${ }^{19}$ Section 4 provides various examples. The function $u(q)=q^{0.01} \ln (q+1.01)$ provides an example of $q_{\ell}$ increasing in $\delta$ (e.g., with $s=0.1, \gamma=0.990001, \beta=0.99$ and $\theta=1.5$ ).
} 
intensive margin effect is $\delta\left(\partial q_{\ell} / \partial \delta\right)\left[u^{\prime}\left(q_{\ell}\right)-c^{\prime}\left(q_{s}\right)\right]+(1-\delta)\left(\partial q_{n} / \partial \delta\right)\left[u^{\prime}\left(q_{n}\right)-c^{\prime}\left(q_{s}\right)\right]<0$. Given $c^{\prime}\left(q_{s}\right)=u^{\prime}\left(q_{\ell}\right)$, the extensive margin effect is $(1-s)\left[u\left(q_{\ell}\right)-u\left(q_{n}\right)-u^{\prime}\left(q_{\ell}\right)\left(q_{\ell}-q_{n}\right)\right]$. By the mean value theorem there is a $q_{m} \in\left(q_{n}, q_{\ell}\right)$ such that $u\left(q_{\ell}\right)-u\left(q_{n}\right)-u^{\prime}\left(q_{m}\right)\left(q_{\ell}-q_{n}\right)=$ 0. Hence, $u\left(q_{\ell}\right)-u\left(q_{n}\right)-u^{\prime}\left(q_{\ell}\right)\left(q_{\ell}-q_{n}\right)>0$.

\section{References}

[1] Aiyagari, S. R., A R. Braun, and Z. Eckstein. "Transaction services, inflation and welfare." Journal of Political Economy 106(6), 1998, 1274-1301.

[2] Aiyagari, S. R., and S. D. Williamson. "Money and dynamic credit arrangements with private information." Journal of Economic Theory 91(2), 2000, 248-79.

[3] Alvarez, F., and F. Lippi. "Financial innovation and the transactions demand for cash." Econometrica 77(2), 2009, 363-402.

[4] Attanasio, O. P., L. Guiso, and T. Jappelli. "The demand for money, financial innovation and the welfare cost of inflation: an analysis with household data." Journal of Political Economy 110(2), 2002, 317-51.

[5] Berentsen, A., G. Camera, and C. Waller. "Money, credit and banking." Journal of Economic Theory 135(1), 2007, 171-95.

[6] Cavalcanti, R., and N. Wallace. "A model of private bank-note issue." Review of Economic Dynamics 2(1), 1999, 104-36.

[7] Chiu, J. and C. Meh. "Financial intermediation, liquidity and inflation." Bank of Canada Working Paper 2008-49, 2008.

[8] Dong, M. "Money and costly credit." Manuscript, Simon Fraser University, 2009.

[9] Dotsey, M. and P. Ireland. The welfare cost of inflation in general equilibrium. Journal of Monetary Economics 37(1), 1996, 29-47. 
[10] Duca, J. V. and W. C. Whitesell. "Credit cards and money demand: a cross-sectional study." Journal of Money, Credit and Banking 27(2), 1995, 604-23.

[11] Economic Report of the President. Washington: U.S. Government Printing Office, 2009.

[12] English, W. B. "Inflation and financial sector size." Journal of Monetary Economics 44(3), 1999, 379-400.

[13] Evans, D. S. and R. Schmalensee. Paying with plastic: the digital revolution in buying and selling. Cambridge: MIT Press, 2005.

[14] Faig, M. and B. Jerez. "Precautionary balances and the velocity of circulation of money." Journal of Money, Credit and Banking 39(4), 2007, 843-73.

[15] Green, E. J. "Central banking and the economics of information." Federal Reserve Bank of Chicago Economic Perspectives 2Q, 2001, 28-37.

[16] He, P., L. Huang, and R. Wright. "Money, banking, and monetary policy." Journal of Monetary Economics 55(6), 2008, 1013-24.

[17] Hoffman, D. L. and R. H. Rasche. "Long-run income and interest elasticities of money demand in the United States." The Review of Economics and Statistics 73(4), 1991, 665-74.

[18] HSN Consultants Inc. The Nilson Report. Oxnard, several years.

[19] Humphrey, D. B. "Replacement of cash by cards in U.S. consumer payments." Journal of Economics and Business 56(3), 2004, 211-25.

[20] Lacker, J. M. and S. L. Schreft. "Money and credit as means of payment". Journal of Monetary Economics 38(1), 1996, 3-23.

[21] Lagos, R. and R. Wright. "A unified framework for monetary theory and policy analysis." Journal of Political Economy 113(2), 2005, 463-84. 
[22] Li, Y. "Banks, private money, and government regulation." Journal of Monetary Economics 53(8), 2006, 2067-83.

[23] Li, Y. "Currency and checking deposits as means of payment." Manuscript, National Taiwan University, 2009.

[24] Lucas, R. E. Jr. "Inflation and welfare." Econometrica 68(2), 2000, 247-74.

[25] Monnet, C. and W. Roberds. "Optimal pricing of payment services." Journal of Monetary Economics 55(8), 2008, 1428-40.

[26] Reed, R. R., and C. Waller. "Money and risk sharing." Journal of Money, Credit and Banking 38(6), 2006, 1599-1618.

[27] Schreft, S. L."Transaction costs and the use of cash and credit." Economic Theory $2(2), 1992,283-96$.

[28] Shi, S. "Credit and money in a search model with divisible commodities." The Review of Economic Studies 63(4), 1996, 627-52.

[29] Simonsen, M. H., and R. P. Cysne. "Welfare costs of inflation and interest-bearing money." Journal of Money, Credit and Banking 33(1), 2001, 90-100.

[30] Telyukova, I. A. "Household need for liquidity and the credit card debt puzzle". Manuscript, University of California, San Diego, 2009.

[31] Telyukova, I. A., and R. Wright. "A model of money and credit, with application to the credit card debt puzzle." Review of Economic Studies 75(2), 2008, 629-47.

[32] U.S. Census Bureau. Statistical Abstract of the United States. Washington: U.S. Government Printing Office, several years.

[33] Williamson, S. D. "Private money." Journal of Money, Credit and Banking 31(3), 1999, 469-91. 
[34] Williamson, S. D. "Limited participation, private money and credit in a spatial model of money." Economic Theory 24(4), 2004, 857-75. 